\title{
MOLECULAR DESIGN STRATEGIES FOR HIGH BIREFRINGENCE LIQUID CRYSTALS
}

\section{SHIN-TSON WU}

School of Optics/CREOL, University of Central Florida, Orlando, FL 32816

\begin{abstract}
Some linearly conjugated liquid crystals with birefringence greater than 0.4 are discussed. UV stability of these high birefringence liquid crystals was systematically investigated. Both electronic conjugation and molecular structure make essential contributions to the observed degradation phenomena. Guidelines for designing stable high birefringence liquid crystals for displays and optical communications are discussed.
\end{abstract}

\section{INTRODUCTION}

Optical phased arrays (OPA) developed by Raytheon and Air Force Research Lab is a versatile device for laser beam steering, adaptive optics, electronic lens, and network switching. ${ }^{1}$ Fig. 1 shows the OPA device structure and its operating principle. The applied stepwise voltages create a phase grating inside the liquid crystal (LC) media that deflects the incoming laser beam to a programmable angle with high precision and high energy efficiency. To steer a $\lambda=1.55 \mu \mathrm{m}$ laser beam, the required $2 \pi$ phase change $(\delta=2 \pi \mathrm{d} \Delta \mathrm{n} / \lambda)$ leads to $\mathrm{d} \Delta \mathrm{n} \sim 1.6$; $\mathrm{d}$ is the LC cell gap and $\Delta \mathrm{n}$ is the birefringence. A thick LC layer would lead to a large phase shift, however, its response time is sluggish because the LC response time is proportional to $\mathrm{d}^{2}$. In order to achieve fast response time while keeping high manufacturing yield, the cell gap is normally kept at $\mathrm{d} \sim 4 \mu \mathrm{m}$. Thus, LC mixtures with $\Delta \mathrm{n} \geq 0.4$ and low viscosity, low optical loss, wide nematic range, and low operating voltage are particularly desirable.

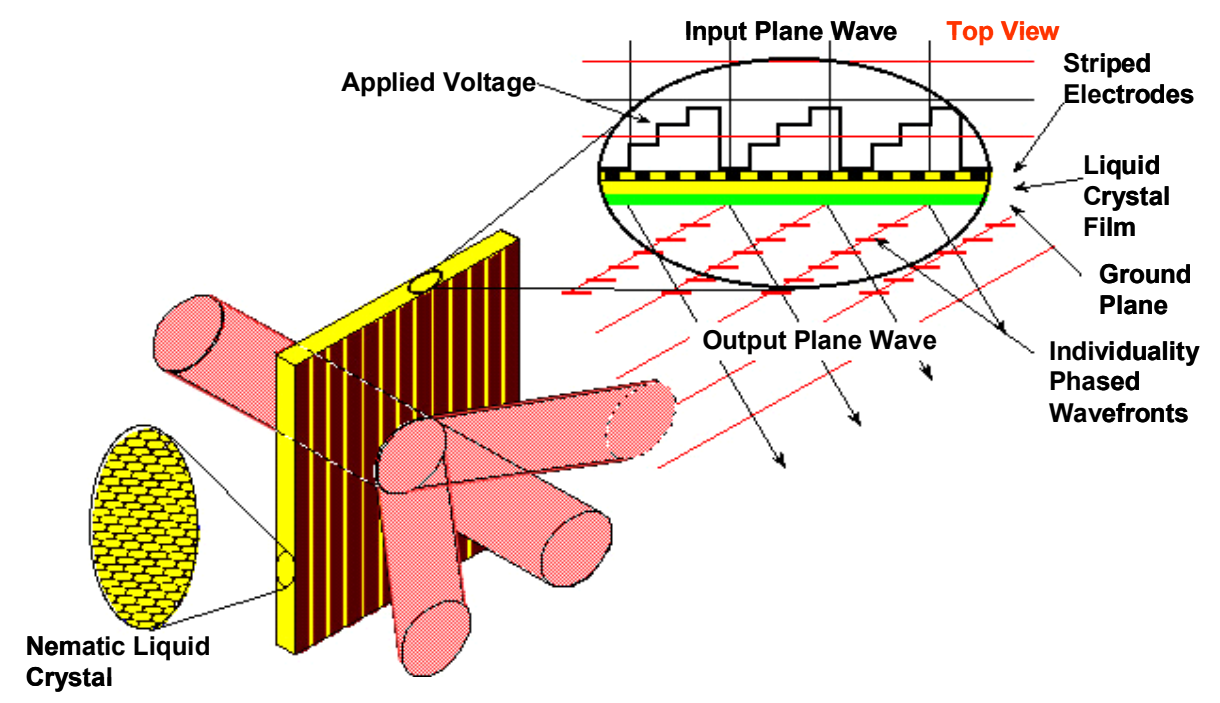

Fig.1 Device structure of a LC-based optical phased array. The applied stepwise voltage generates LC phase grating and deflects the incoming laser beam. 
High melting temperature, increased viscosity and degraded photo and thermal stability are the major concerns for high $\Delta \mathrm{n}$ LCs. Eutectic mixture is a common approach for lowering the melting point. It is common for a commercial mixture to consist of 5-10 components. Elevated temperature operation is an efficient way for reducing viscosity. For every $10^{\circ} \mathrm{C}$ temperature increase, viscosity is decreased by $\sim 2 \mathrm{X}$. To prevent LC material from interacting with moistures, a LC cell is hermetically sealed. An incoherent UV light is used to cure the glue lines before injecting LC mixture and then plug the hole after vacuum filling the LC device. Thus, the LC material has to withstand UV exposure to certain extent, say $\mathrm{I} \sim 100 \mathrm{mw} / \mathrm{cm}^{2}$ for few minutes.

\section{LC COMPOUNDS WITH $0.4<\Delta \mathrm{n}<0.5$}

In this category, diphenyl-diacetylenes and tolanes are chosen as examples for discussion. Diphenyl-diacetylenes exhibit high birefringence, low viscosity and wide nematic range, however, their photo and thermal stability is inadequate. On the other hand, tolanes show better stability except their molecular conjugation is not long enough. A polar electron acceptor such as $\mathrm{CN}$ or NCS needs to be linked to the core in order to boost $\Delta \mathrm{n}$.

Diphenyl-diacetylenes (PTTP)

The molecular structures of diphenyl-diacetylene ${ }^{2}$ liquid crystals (abbreviated as PTTP; $\mathrm{P}=$ phenyl ring, $\mathrm{T}=$ carbon-carbon triple bond) are shown below:

$$
\text { F or Alky } \longrightarrow \mathrm{C}=\mathrm{C}-\mathrm{C} \equiv \mathrm{C} \longrightarrow \mathrm{C}_{\mathrm{n}} \mathrm{H}_{2 \mathrm{n}+1}
$$

Both alkyl and alkenyl fluoro PTTP homologues have been studied. ${ }^{3-5}$ Replacing the alkyl by an alkenyl side chain dramatically enhances the clearing point and widens the nematic range. ${ }^{6}$ High clearing point also plays an important role in enhancing $\Delta \mathrm{n}$ due to higher order parameter. Mixtures consisting of these olefin PTTP homologues exhibit $\Delta \mathrm{n} \sim 0.43$ at $\lambda=633 \mathrm{~nm}$ and $\mathrm{T}=20^{\circ} \mathrm{C}$.

Inadequate photo and thermal stability is the major concern for the PTTP LCs. ${ }^{7}$ Fig. 2 shows the measured voltage-dependent transmittance (between crossed polarizers) of a homogeneous cell before and after UV exposure. A mercury lamp with peak wavelength at $\lambda \sim 365 \mathrm{~nm}$ and a binary mixture PTTP-24/36 (50\% PTTP-24 and 50\% PTTP-36) were used for experiments. A HeNe laser beam was used to probe the transmittance change during exposure. Dots and squares represent measured results before and after 65 seconds of exposure at $\mathrm{I} \sim 50 \mathrm{mw} / \mathrm{cm}^{2}$, respectively.

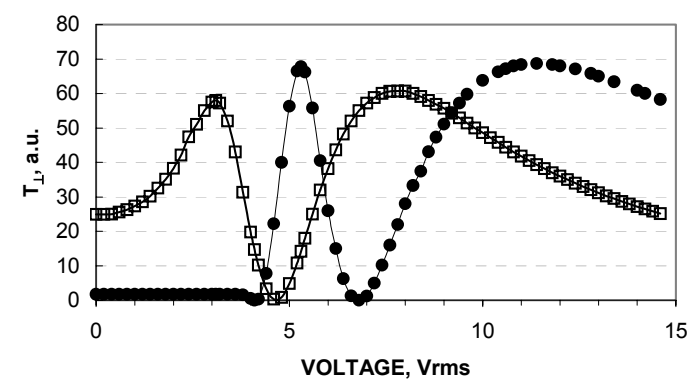

Fig.2 The voltage-dependent transmittance of a homogeneous LC cell before (dots) and after (squares) UV exposure. UV intensity $\mathrm{I}=50 \mathrm{mw} / \mathrm{cm}^{2}$. Cell gap $\mathrm{d}=3.74 \mu \mathrm{m}$ and $\mathrm{T}=22^{\circ} \mathrm{C}$. Alignment layer is a buffed polyimide film. Crossed polarizers. $\lambda=633 \mathrm{~nm}$.

From Fig.2, three general phenomena are observed as degradation takes place: 1 . The effective $\Delta \mathrm{n}$ is decreased, 2 . The threshold voltage is smeared and decreased, and 3. The light scattering is 
gradually intensified. The degradation mechanism is believed to originate from the UV-induced free radicals of the diacetylene group. These free radicals transfer charges to the neighboring PTTP molecules, converting triple bond into double bond, and initiating the polymerization process from front surface layers and gradually migrating into bulk as UV dosage increases. Once the surface layers are cross-linked, the surface alignment is disturbed resulting in a reduced $\Delta \mathrm{n}$, increased viscosity, smeared threshold voltage, and increased light scattering.

Figures 3 (a) and (b) show the photos of the homogeneous PTTP-24/36 cell taken under a polarizing optical microscope before and after UV exposure, respectively. Before UV exposure, the cell shows uniform green color between crossed-polarizers. After 65 seconds of exposure at $\mathrm{I} \sim 50 \mathrm{mw} / \mathrm{cm}^{2}$, the cell turned to different color and some cross-linking textures appeared. These polymerized clusters scatter light, disturb LC alignment and increase pretilt angle. As a result, the observed $\Delta \mathrm{n}$ is decreased, and threshold voltage is smeared and reduced.

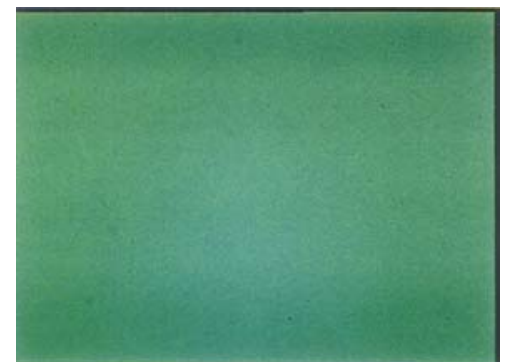

(a)

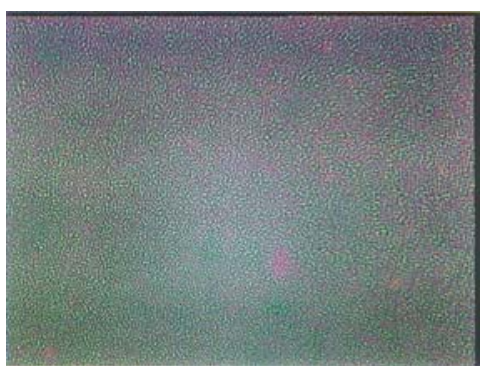

(b)

Fig.3 Microscope photos of a 6- $\mu \mathrm{m}$ homogeneous LC cell before (a) and after (b) UV exposure for 65 seconds. Note the color change and polymerized textures in (b).

To retard the polymerization process, an UV scavenger as shown below has been found. ${ }^{8}$ Adding $10 \%$ of a nitro-amino tolane to the PTTP-24/36 mixture, the UV stability is improved by $30 \mathrm{X}$.<smiles>O=[N+]([O-])c1ccc(C#Cc2ccc(NC(=S)[SH2+])cc2)cc1</smiles>

\section{PTPT Compounds}

If diacetylene is indeed responsible for causing material instability, then its isomer PTPT with alternating phenyl ring and acetylene group as shown below should have a better UV stability:

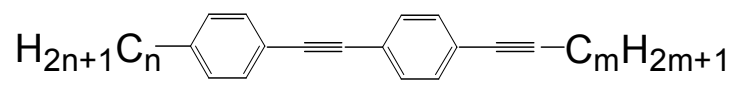

Table I lists the phase transition temperatures of some PTPT compounds. From Table I, these PTPT compounds exhibit either monotropic phase or no LC phase at all. The monotropic phase is undesirable from mixture standpoint owing to its high melting temperature. For a normal LC, we prefer low melting and high clearing points.

Table I Phase transition temperatures of some Chisso and Merck PTPT-nm compounds. 


\begin{tabular}{|c|c|c|}
\hline $\mathrm{n}$ & $\mathrm{m}$ & Phase Transition $\left({ }^{\circ} \mathrm{C}\right)$ \\
\hline 2 & 2 & $\mathrm{~K} 83.1 \mathrm{I}$ \\
\hline 2 & 3 & $\mathrm{~K} 89.8 \mathrm{I}$ \\
\hline 3 & 1 & $\mathrm{~K} 87.7 \mathrm{~N}(85.1) \mathrm{I}$ \\
\hline 3 & 2 & $\mathrm{~K} 100.1 \mathrm{~N}(48.7) \mathrm{I}$ \\
\hline 3 & 3 & $\mathrm{~K} 78.0 \mathrm{~N}(54.0) \mathrm{I}$ \\
\hline 3 & 5 & $\mathrm{~K} 72.0 \mathrm{~N}(40.4) \mathrm{I}$ \\
\hline 4 & 1 & $\mathrm{~K} 81.0 \mathrm{~N}(56.9) \mathrm{I}$ \\
\hline 4 & 2 & $\mathrm{~K} 87.6 \mathrm{~N}(76.8) \mathrm{I}$ \\
\hline 4 & 3 & $\mathrm{~K} 100.9 \mathrm{~N}(65.0) \mathrm{I}$ \\
\hline 4 & 4 & $\mathrm{~K} 84.3 \mathrm{I}$ \\
\hline 5 & 2 & $\mathrm{~K} 80.8 \mathrm{~N}(46.1) \mathrm{I}$ \\
\hline 5 & 3 & $\mathrm{~K} 76.2 \mathrm{~N}(50.3) \mathrm{I}$ \\
\hline
\end{tabular}

The UV absorption of PTPT-35 (circles) was measured and results are compared with those of PTTP-24 (squares) as shown in Fig.4. Although these two LCs are isomers, PTTP has a more effective electron conjugation than PTPT so that its absorption tail is longer.

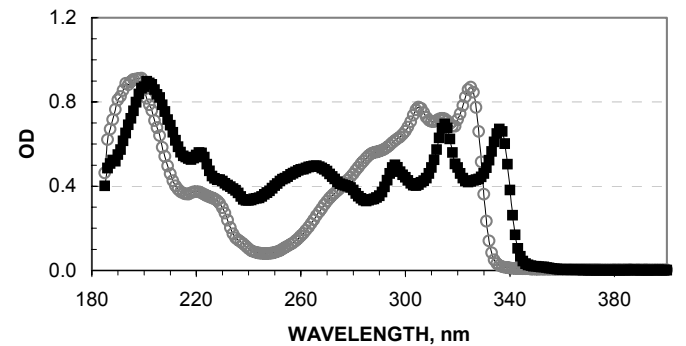

Fig.4. Measured optical density of PTPT-35 (gray) and PTTP-24 (black). Concentration $=1 \%, \mathrm{~d}=6 \mu \mathrm{m}$, and host ZLI-2359.

We studied the UV stability of PTPT-35 using two different LC alignments: rubbed polyimide (PI) and evaporated $\mathrm{SiO}_{2}$ layer. For this study, we mixed 20\% PTPT-35 in ZLI-2359. The homogeneous cell with $\mathrm{SiO}_{2}$ alignment last $\sim 40$ minutes (at $\mathrm{I} \sim 50 \mathrm{mw} / \mathrm{cm}^{2}$ ) before it turned to homeotorpic cell. By contrast, the PI cell last for $\sim 60$ minutes. Since PI is less transparent than $\mathrm{SiO}_{2}$, it helps shield some UV light and prolong the cell life accordingly. The extrapolated lifetime for PTPT-35 is about 8 minutes which, indeed, is better than that of PTTP-24/36.

\section{$\underline{\text { Tolanes (PTP) }}$}

Table II lists some selected high $\Delta \mathrm{n}$ polar tolanes. The cyano $(\mathrm{CN})^{9}$ and isothiocyanato $(\mathrm{NCS})^{10}$ tolanes exhibit either monotropic or smectic phase so that they are unfavorable for forming nematic mixtures. Replacing the alkyl side chain with an olefin group, the monotropic phase is converted to enantiotropic nematic phase. ${ }^{11}$ These olefin tolanes possess a wide nematic range, lower melting point, and higher $\Delta \mathrm{n}$ as compared to their corresponding alkyl compounds. From Table II, several polar tolanes have extrapolated $\Delta \mathrm{n}$ greater than 0.4 .

Table II Physical properties of some polar tolane derivatives. Here, K, N, and I represent crystalline, nematic and isotropic phase, respectively, () stands for monotropic phase transition, $\mathrm{Ph}$ in column $\mathrm{Y}$ stands for a phenyl ring. 


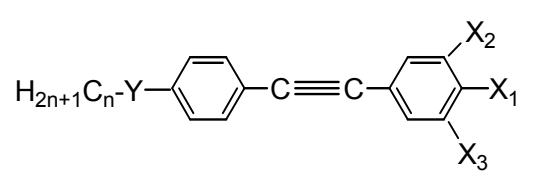

\begin{tabular}{cccclll}
\hline $\mathrm{X}_{1}$ & $\mathrm{X}_{2}$ & $\mathrm{X}_{3}$ & $\mathrm{n}$ & $\mathrm{Y}$ & Phase Transitions & $\Delta \mathrm{n}$ \\
\hline $\mathrm{CN}$ & $\mathrm{H}$ & $\mathrm{H}$ & 3 & - & K 87 N (78) I & \\
$\mathrm{CN}$ & $\mathrm{H}$ & $\mathrm{H}$ & 3 & $\mathrm{O}$ & K 98 N 103 I & \\
$\mathrm{CN}$ & $\mathrm{H}$ & $\mathrm{H}$ & 3 & $\equiv$ & K 119 N (87) I & 0.46 \\
$\mathrm{CN}$ & $\mathrm{H}$ & $\mathrm{H}$ & 3 & $=$ & K 100 N 150 I & 0.47 \\
$\mathrm{CN}$ & $\mathrm{F}$ & $\mathrm{H}$ & 3 & $\equiv$ & K 109 I & 0.41 \\
$\mathrm{CN}$ & $\mathrm{F}$ & $\mathrm{H}$ & 3 & $=$ & K 74 N 102 I & 0.43 \\
$\mathrm{CN}$ & $\mathrm{H}$ & $\mathrm{H}$ & 4 & $\mathrm{~S}$ & K 80 N (53) I & 0.34 \\
$\mathrm{NCS}$ & $\mathrm{H}$ & $\mathrm{H}$ & 4 & $\mathrm{~S}$ & K 85 SmB 85 N (65) I & 0.49 \\
$\mathrm{NCS}$ & $\mathrm{H}$ & $\mathrm{H}$ & 5 & - & K 92 SmA (82) I & \\
$\mathrm{NCS}$ & $\mathrm{F}$ & $\mathrm{F}$ & 4 & $\mathrm{O}$ & K 71 N (62) I & 0.41 \\
NCS & $\mathrm{F}$ & $\mathrm{F}$ & 4 & Ph & K 63 SmA 100 N 209 I & 0.46 \\
\hline
\end{tabular}

Both $\mathrm{CN}$ and NCS polar groups are effective electron acceptors. They extend the electron conjugation along the principal molecular axis so that the LC birefringence is significantly enhanced. They also possess a large dipole moment (CN 4Debye and NCS 3.6Debye). A drawback of the cyano compounds is that they tend to form dimers so that their viscosity is relatively large. From performance viewpoint, NCS group seems to be a favored choice. However, NCS tolanes tend to favor smectic phase and their synthesis procedures are more sophisticated.

To overcome smectic phase and obtain a wide nematic range, a cyclohexane ring has been introduced to the tolane core. ${ }^{12}$ The molecular structure is shown as following:

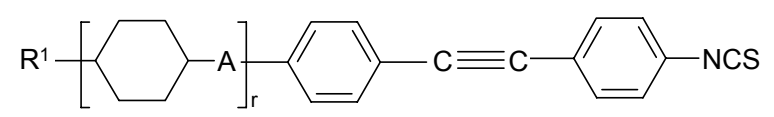

where $\mathrm{r}=1$ or 0 , $\mathrm{A}$ is a single bond or $-\mathrm{CH}_{2} \mathrm{CH}_{2}$ - group, and $\mathrm{R}^{1}=\mathrm{C}_{\mathrm{n}} \mathrm{H}_{2 \mathrm{n}+1}$ or $\mathrm{C}_{\mathrm{n}} \mathrm{H}_{2 \mathrm{n}+1} \mathrm{O}$.

The phase transition temperatures and heat fusion enthalpy of these NCS tolanes are listed in Table III. From Table III, the alkyl and alkoxy NCS tolanes (items 1-6) possess either no LC phase, smectic phase, or narrow nematic phase, depending on the chain length. The cyclohexane NCS tolanes (items 7-10) exhibit a wide nematic range, except that their melting point is quite high. Inserting an ethylene $\left(\mathrm{C}_{2} \mathrm{H}_{4}\right)$ linking group (item 11-13) lowers the melting point by about $10^{\circ} \mathrm{C}$. However, their birefringence is slightly reduced and viscosity increased, as compared with the parent homologues. 
Table III Phase transition temperatures $\left[{ }^{\circ} \mathrm{C}\right]$ and heat fusion enthalpies $[\mathrm{kcal} / \mathrm{mol}]$ of some isothiocyanatotolanes.

\begin{tabular}{|c|c|c|c|c|c|c|c|c|c|c|}
\hline $\mathbf{N o}$ & $\mathbf{R}$ & $\mathbf{r}$ & $\mathbf{A}$ & $\mathbf{C r}$ & & $\mathbf{S m A}$ & & $\mathbf{N}$ & & Iso \\
\hline $\mathbf{1}$ & $\mathrm{C}_{3} \mathrm{H}_{7}$ & 0 & - & $*$ & $\begin{array}{c}96.6 \\
(4.66)\end{array}$ & - & & - & & $*$ \\
\hline $\mathbf{2}$ & $\mathrm{C}_{5} \mathrm{H}_{11}$ & 0 & - & $*$ & $\begin{array}{c}90.5 \\
(6.49)\end{array}$ & - & & - & & $*$ \\
\hline $\mathbf{3}$ & $\mathrm{C}_{2} \mathrm{H}_{5} \mathrm{O}$ & 0 & - & $*$ & $\begin{array}{c}127.2 \\
(5.71)\end{array}$ & - & & - & & $*$ \\
\hline $\mathbf{4}$ & $\mathrm{C}_{3} \mathrm{H}_{7} \mathrm{O}$ & 0 & - & $*$ & $\begin{array}{c}125.3 \\
(5.67)\end{array}$ & - & & - & & $*$ \\
\hline $\mathbf{5}$ & $\mathrm{C}_{4} \mathrm{H}_{9} \mathrm{O}$ & 0 & - & $*$ & $\begin{array}{c}112.1 \\
(5.36)\end{array}$ & $*$ & $\begin{array}{c}112.5^{+} \\
(3.16)\end{array}$ & $*$ & $\begin{array}{c}116.0 \\
(0.19)\end{array}$ & $*$ \\
\hline $\mathbf{6}$ & $\mathrm{C}_{5} \mathrm{H}_{11} \mathrm{O}$ & 0 & - & $*$ & $\begin{array}{c}69.6 \\
(5.83)\end{array}$ & $*$ & $\begin{array}{c}112.5^{+} \\
(3.30)\end{array}$ & - & & $*$ \\
\hline $\mathbf{7}$ & $\mathrm{C}_{2} \mathrm{H}_{5}$ & 1 & single bond & $*$ & $\begin{array}{c}140.2 \\
(6.14)\end{array}$ & - & & $*$ & $\begin{array}{c}243.0 \\
(0.20)\end{array}$ & $*$ \\
\hline $\mathbf{8}$ & $\mathrm{C}_{3} \mathrm{H}_{7}$ & 1 & single bond & $*$ & $\begin{array}{c}137.2 \\
(6.34)\end{array}$ & - & & $*$ & $\begin{array}{c}265.4 \\
(0.35)\end{array}$ & $*$ \\
\hline $\mathbf{9}$ & $\mathrm{C}_{4} \mathrm{H}_{9}$ & 1 & single bond & $*$ & $\begin{array}{c}106.9 \\
(5.23)\end{array}$ & $*$ & $\begin{array}{c}139.9 \\
(0.024)\end{array}$ & $*$ & $\begin{array}{c}257.4 \\
(0.20)\end{array}$ & $*$ \\
\hline $\mathbf{1 0}$ & $\mathrm{C}_{5} \mathrm{H}_{11}$ & 1 & single bond & $*$ & $\begin{array}{c}119.5 \\
(6.29)\end{array}$ & $*$ & $\begin{array}{c}147.6 \\
(0.064)\end{array}$ & $*$ & $\begin{array}{c}254.9 \\
(0.34)\end{array}$ & $*$ \\
\hline $\mathbf{1 1}$ & $\mathrm{C}_{3} \mathrm{H}_{7}$ & 1 & $-\mathrm{CH}_{2} \mathrm{CH}_{2-}$ & $*$ & $\begin{array}{c}130.0 \\
(6.22)\end{array}$ & - & & $*$ & $\begin{array}{c}211 \\
(0.64)\end{array}$ & $*$ \\
\hline $\mathbf{1 2}$ & $\mathrm{C}_{4} \mathrm{H}_{9}$ & 1 & $-\mathrm{CH}_{2} \mathrm{CH}_{2-}$ & $*$ & $\begin{array}{c}100.8 \\
(5.41)\end{array}$ & $(*$ & $95.2)$ & $*$ & $\begin{array}{c}205.7 \\
(0.62)\end{array}$ & $*$ \\
\hline $\mathbf{1 3}$ & $\mathrm{C}_{5} \mathrm{H}_{11}$ & 1 & $-\mathrm{CH}_{2} \mathrm{CH}_{2-}$ & $*$ & $\begin{array}{c}114.1 \\
(6.58)\end{array}$ & $(*$ & $100.5)$ & $*$ & $\begin{array}{c}207.0 \\
(0.70)\end{array}$ & $*$ \\
\hline
\end{tabular}

+ - smectic E phase

It should be mentioned that the LC compounds containing CN or NCS group usually exhibit a low resistivity and are not suitable for active matrix addressed display applications. However, recent studies ${ }^{13}$ show that if at least $\mathrm{X}_{2}$ or $\mathrm{X}_{3}$ is a fluoro group, the voltage holding ratio is boosted to $98 \%$. Such fluoro group also contributes to enhance the dielectric anisotropy and lower melting temperature. A tradeoff is in the increased viscosity.

We also measured the UV stability of pentyl-isothiocyanato-tolane, which is abbreviated as PTP-5NCS. Results are depicted in Fig. 5. Since PTP-5NCS is a smectic, we mixed 20\% of it in an UV transparent nematic mixture ZLI-2359. A $6-\mu \mathrm{m}$ homogeneous cell was prepared for UV tests. A HeNe laser was used to probe the electro-optic properties of the LC cell. From Fig.5, the UV stability of PTP-5NCS is about 40 minutes ( $=200$ minutes $\times 20 \%)$ at $\mathrm{I} \sim 50 \mathrm{mw} / \mathrm{cm}^{2}$ exposure intensity, which is much better than that of the PTTP and PTPT compounds.

The absorption wavelengths of PTTP-4F and PTP-5NCS are similar, as shown in Fig.6. However, PTP-5NCS has much better UV stability than PTTP-4F. Therefore, electronic transition wavelength is not the sole factor affecting the material stability. Detailed molecular structure also plays an important role. 


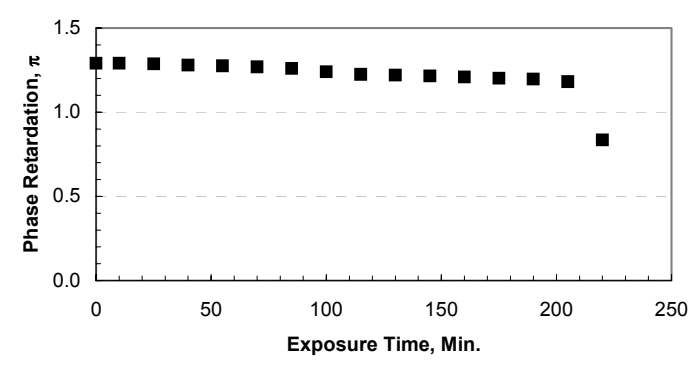

Fig.5 The measured phase retardation of a $6-\mu \mathrm{m}$ homogeneous cell containing $20 \%$ PTP-5NCS in ZLI-2359. UV intensity I $\sim 50 \mathrm{mw} / \mathrm{cm}^{2} . \lambda=633 \mathrm{~nm}$.

\section{LCs WITH $\Delta \mathrm{n}>0.5$}

Two series of LC compounds with $\Delta \mathrm{n}>0.5$ (at $\lambda=589 \mathrm{~nm}$ and room temperature) have been investigated. They are bistolanes and isothiocyanato naphthalene tolanes.

\section{$\underline{\text { Bistolanes }}$}

Bistolanes $^{14}$ exhibit a high $\Delta \mathrm{n}$ due to their long molecular conjugation. However, as the conjugation length increases, their melting point also increases. Based on the Schröder-van Laar equation, high melting point leads to a poor solubility while forming eutectic mixtures. An effective way for lowering melting point is to substitute a lateral alkyl group in the middle phenyl ring, as shown below, to widen the molecular separation: ${ }^{15}$

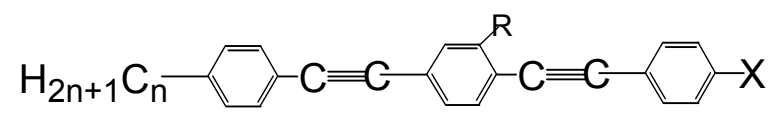

Here, X can be an F or CN group, and R can be a hydrogen, methyl, ethyl or fluoro group.

Table IV lists the phase transition temperatures of some fluoro and cyano bistolanes. The compound with $\mathrm{R}=\mathrm{H}$ has melting point as high as $173^{\circ} \mathrm{C}$. Thus, its solubility is limited to $5 \%$. With a fluoro substitution, the melting point is decreased to $146^{\circ} \mathrm{C}$. In the case that $\mathrm{R}=\mathrm{CH}_{3}$, the melting point is reduced to $69^{\circ} \mathrm{C}$. Continuing to increase the lateral side chain length, e.g., $\mathrm{C}_{2} \mathrm{H}_{5}$, further lowers the melting point except that its viscosity increases substantially. The extrapolated $\Delta \mathrm{n}$ of a cyano bistolane (with $\mathrm{R}=\mathrm{CH}_{3}$ ) is 0.53 at $\lambda=633 \mathrm{~nm}$ and $\mathrm{T}=22^{\circ} \mathrm{C}$.

Table IV Phase transitions (in ${ }^{\circ} \mathrm{C}$ ) and heat fusion enthalpy ( $\left.\mathrm{kcal} / \mathrm{mol}\right)$ of some bistolanes.

\begin{tabular}{|l|l|l|l|l|l|}
\hline $\mathrm{n}$ & $\mathrm{R}$ & $\mathrm{X}$ & $\mathrm{T}_{\mathrm{mp}}$ & $\mathrm{T}_{\mathrm{c}}$ & $\Delta \mathrm{H}$ \\
\hline 4 & $\mathrm{H}$ & $\mathrm{F}$ & 173 & 207 & 7.6 \\
\hline 4 & $\mathrm{~F}$ & $\mathrm{~F}$ & 146 & 170 & 6.5 \\
\hline 5 & $\mathrm{Me}$ & $\mathrm{F}$ & 69 & 163 & 5.0 \\
\hline 5 & $\mathrm{Et}$ & $\mathrm{F}$ & 61 & 103 & 5.2 \\
\hline 5 & $\mathrm{Me}$ & $\mathrm{CN}$ & 114 & 203 & 5.5 \\
\hline 5 & $\mathrm{Et}$ & $\mathrm{CN}$ & 85 & 159 & 3.5 \\
\hline
\end{tabular}


As the molecular conjugation length increases, the LC becomes bulkier so that its viscosity also increases. To reduce viscosity, elevated temperature $\left(40-50^{\circ} \mathrm{C}\right)$ operation has been commonly considered. Roughly speaking, the visco-elastic coefficient $\left(\gamma_{1} / \mathrm{K}\right)$ decreases two times as the operating temperature increases by every $15^{\circ} \mathrm{C}$.

The UV stability of a dialkyl bistolane PTP"TP-53 was studied. At I=50mw $/ \mathrm{cm}^{2}$ intensity, PTP"TP-53 can only withstand about 2 minutes of UV exposure before degradation takes place. The photo stability of a LC is determined by its absorption wavelength and chemical structure. Fig.6 shows the absorption wavelength of three compounds studied: PTTP-4F, PTP-5NCS and PTPTP-25. In these measurements, $1 \%$ of the guest compound was dissolved in ZLI-2359. A $\mathrm{d} \sim 6 \mu \mathrm{m}$ homogeneous cell was used for the absorption measurements. From Fig.6, the absorption tail of PTPTP- 25 is close to the peak UV light $(\lambda \sim 365 \mathrm{~nm})$. Thus, its UV stability is much worse than that of PTP-5NCS.

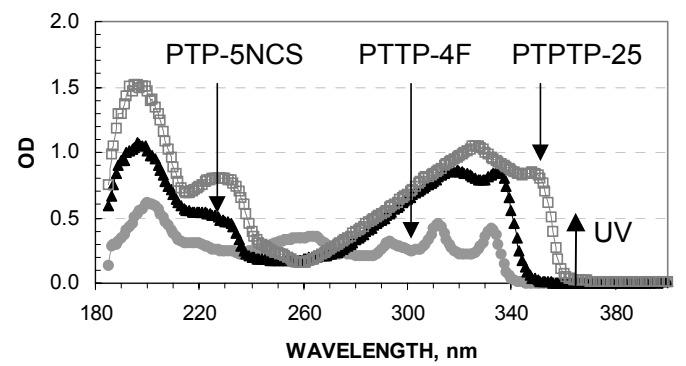

Fig.6 The UV absorption spectra of PTTP-4F, PTP-5NCS and PTPTP-52. Concentration $=1 \%$, cell gap $\mathrm{d}=6 \mu \mathrm{m}$ and host $\mathrm{LC}$ is ZLI-2359.

Also observed from Fig.6, the absorption tail of PTTP-4F and PTP-5NCS extends to $340 \mathrm{~nm}$ and $350 \mathrm{~nm}$, respectively. Although PTP-5NCS has a slightly longer absorption, it can still withstand $\sim 40$ minutes of UV irradiation as compared to 30 seconds for PTTP-4F. Thus, chemical structure also plays an important role in determining the UV and thermal stability.

Isothiocyanato Naphthalene Tolanes

Another series of nematic LC with $\Delta \mathrm{n}>0.5$ is the isothiocyanato naphthalene tolane (with structure shown below). ${ }^{16}$ Two homologues have been synthesized. Their phase transition temperatures and heat fusion enthalpy are listed in Table V for comparison.

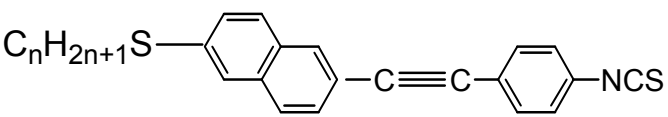

Table V Phase transitions (in ${ }^{\circ} \mathrm{C}$ ) and heat fusion enthalpy $(\mathrm{kcal} / \mathrm{mol})$ of two naphthalene tolane homologues.

\begin{tabular}{|c|l|c|}
\hline $\mathrm{n}$ & $\begin{array}{l}\text { Phase } \\
\text { Transitions }\end{array}$ & $\Delta \mathrm{H}$ \\
\hline 3 & K 113 N 126 I & 7.2 \\
\hline 4 & K 95 N 135 I & 5.1 \\
\hline
\end{tabular}


These two naphthalene tolanes all exhibit nematic phase. The $n=4$ homologue has a lower melting point and wider nematic range. Its extrapolated birefringence is as high as 0.54 at $\lambda=589 \mathrm{~nm}$ and room temperature. The naphthalene group not only lengthens the molecular conjugation, but also suppresses the smectic phase. Its viscosity and photo and thermal stability have not been evaluated.

\section{LC ABSORPTION}

\section{Visible to Near IR}

For high power IR laser beam steering, the LC absorption is a critical issue because some overtone molecular vibrations exist. Two factors contribute to the optical loss: light scattering and absorption. To suppress light scattering, the LC mixture under study was heated to an isotropic state. In addition, in order to take surface reflections into consideration, a 1-mm gap quartz cell was used in the reference channel and a $2-\mathrm{cm}$ cell used as sample. Therefore, the measured optical loss is equivalent to a $1.9-\mathrm{cm}$ LC layer. For such absorption measurements, about $1 \mathrm{~g}$ of sample is required. Thus, we chose Merck E7 mixture $\left(\mathrm{T}_{\mathrm{c}}=60^{\circ} \mathrm{C}\right)$ for such studies. Both sample and reference cells were controlled at $\mathrm{T} \sim 70^{\circ} \mathrm{C}$. Results are depicted in Fig. 7 .

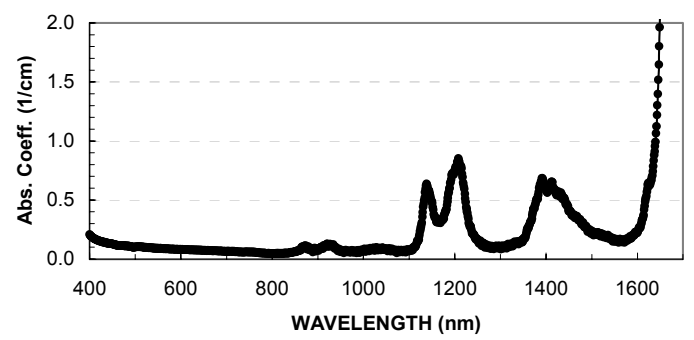

Fig.7 Measured absorption coefficient of an E7 LC cell in the visible and near IR regimes at $\mathrm{T} \sim 70^{\circ} \mathrm{C} . \mathrm{d}=1.9-\mathrm{cm}$.

From Fig.7, E7 has relatively small absorption in the visible region. This is because the $\pi \rightarrow \pi^{*}$ electronic transitions of E7 are located in the UV region. In the visible region, absorption decreases. The absorption minimum occurs at $\lambda \sim 850 \mathrm{~nm}$. At $\lambda=1.06 \mu \mathrm{m}, \alpha \sim 0.08 \mathrm{~cm}^{-1}$. Thus, the LC-based OPA should be able to steer high power YAG laser beams. Usually, in a LC panel, the conductive and transparent ITO layer has the lowest damage threshold $\left(\sim 200 \mathrm{MW} / \mathrm{cm}^{2}\right)$. To avoid laser-induced phase transition to occur, a high clearing point LC mixture is desired.

Beyond $\lambda=1.1 \mu \mathrm{m}$, the overtone vibration starts to appear. At $\lambda=1.3$ and $1.55 \mu \mathrm{m}$, the LCs we studied all exhibit a local absorption minimum. ${ }^{17}$ At these two wavelengths, the absorption coefficients of E7 are 0.1 and $0.15 / \mathrm{cm}$, respectively. Suppose a $5-\mu \mathrm{m}$ cell gap is used for the $\lambda=1.55 \mu \mathrm{m}$ optical switch, the absorption loss is quite negligible.

\section{Mid IR}

In the longer IR region $(\lambda>2.1 \mu \mathrm{m})$, several overtone molecular vibration bands exist and overlap closely. As a result, the background absorption coefficient reaches $\alpha \sim 10 \mathrm{~cm}^{-1}$, as shown in Fig. 8 . For a $5-\mu \mathrm{m}$ cell, the absorption loss accounts for $0.5 \%$. The absorbed laser light will be converted to heat and warm up the LC medium. 


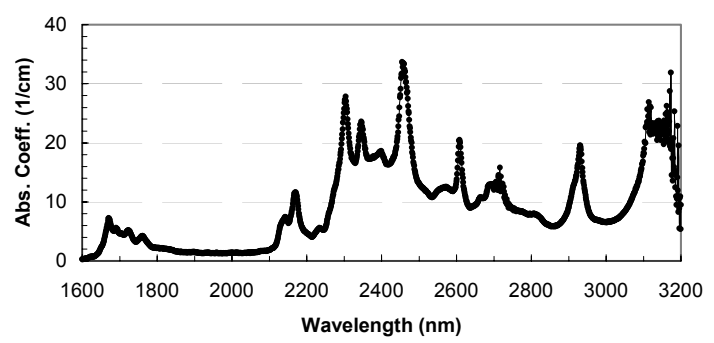

Fig. 8 Measured IR absorption coefficient of an E7 LC cell at T $70^{\circ} \mathrm{C} . \mathrm{d}=1.9 \mathrm{~cm}$.

\section{CONCLUSIONS}

We report several high birefringence $(\Delta \mathrm{n}>0.4)$ LC compounds for electro-optic applications. These linearly conjugated liquid crystals generally exhibit high melting temperature, increased viscosity, and decreased UV stability. Therefore, an optimal molecular structure should exist for balancing all the required physical properties, such as nematic range, birefringence, viscosity, operating voltage, optical loss, and material stability. Molecular modeling and simulations before compound synthesis are highly desirable.

\section{ACKNOWLEDGMENT}

This work was supported by AFOSR under contract number F49620-01-1-0377. The author is indebted to Dr. Terry Dorschner of Raytheon Lexington Lab for technical discussions, professors Roman Dabrowski and Alex Seed for material syntheses.

\section{REFERENCES}

1. P. F. McManamon et al, Proc. IEEE $\underline{84}, 268$ (1996)

2. B. Grant, Mol. Cryst. Liq. Cryst. $\underline{48}, 175$ (1978).

3. S. T. Wu et al, Appl. Phys. Lett. 61,635 (1992).

4. S. T. Wu et al, Appl. Phys. Lett., 64, 1204, (1994).

5. S. T. Wu et al, Appl. Phys. Lett. 77, 957 (2000).

6. S. T. Wu and M. Neubert, U.S. patent 6,312,618 (2001).

7. M. D. Wand et al, Ferroelectrics 180, 333 (1996).

8. S. T. Wu and D. K. Yang, "Reflective Liquid Crystal Displays" (Wiley-SID, 2001).

9. G. W. Gray et al, MCLC 37, 213 (1976).

10. G. J. Cross, et al, J. Mater. Chem. 10, 1555 (2000).

11. C. Sekine et al, MCLC 332, 235 (1999).

12. A. Spadlo et al, Proc. SPIE (in press).

13. Y. B. Kim and B. H. Kim, SID Tech. Digest, $\underline{31}, 874$ (2000).

14. Y. Goto and K. Kitano, EP 345,013 (1989).

15. S. T. Wu et al, JJAP 39, L38 (2000).

16. A. J. Seed et al, J. Mater. Chem., 10, 2069 (2000).

17. S. T. Wu, J. Appl. Phys. 84, 4462 (1998). 